\title{
Managing urinary tract infections
}

\author{
Sermin A. Saadeh • Tej K. Mattoo
}

Received: 1 October 2010 /Revised: 25 January 2011 / Accepted: 28 January 2011 / Published online: 16 March 2011

(C) IPNA 2011

\begin{abstract}
Urinary tract infections (UTI) are common in childhood. Presence of pyuria and bacteriuria in an appropriately collected urine sample are diagnostic of UTI. The risk of UTI is increased with an underlying urological abnormality such as vesicoureteral reflux, constipation, and voiding dysfunction. Patients with acute pyelonephritis are at risk of renal scarring and subsequent complications such as hypertension, proteinuria with and without FSGS, pregnancy-related complications and even end-stage renal failure. The relevance and the sequence of the renal imaging following initial UTI, and the role of antimicrobial prophylaxis and surgical intervention are currently undergoing an intense debate. Prompt treatment of UTI and appropriate follow-up of those at increased risk of recurrence and/or renal scarring are important.
\end{abstract}

Keywords Urinary tract infection. Vesicoureteric reflux . Management

\section{Introduction}

Urinary tract infection (UTI) is a common illness in children, with overall prevalence ranging from $2 \%$ to $8 \%$ throughout childhood [1-3]. It can be associated with long-

\footnotetext{
S. A. Saadeh

Pediatric Nephrology and Hypertension, Children's Hospital of Michigan, Wayne State University,

Detroit, MI, USA

T. K. Mattoo $(\bowtie)$

Children's Hospital of Michigan, Pediatric Nephrology and Hypertension, Wayne State University School of Medicine, 3901 Beaubien St,

Detroit, MI 48201, USA

e-mail: tmattoo@med.wayne.edu
}

term sequela of renal scarring, which may cause hypertension, proteinuria, pregnancy-related complications, or even progressive renal failure. The risk of recurrent UTI in children has been estimated to be $12-30 \%$ in the first 6-12 months after the initial UTI [4, 5]. Predisposing factors for recurrence include vesicoureteral reflux and dysfunctional elimination [6-8].Escherichia coli remains the most common organism causing UTI in children $(60$ 92\%). Other common organisms include Klebsiella, Proteus, Enterococcus, and Enterobacter spp. [9-11]. Less common organisms such as Pseudomonas, Group B Streptococcus, and Staphylococcus aureus are seen with increased frequency in patients with anatomical defects, kidney stones, following genitourinary surgery or bladder catheterization, and following repeated courses with antibiotic treatments $[3,8]$. The pathogenetic mechanism of UTI is thought to be an ascending infection from periurethral organisms in children older than the neonatal period. Factors contributing to infection include bacterial virulence factors as well as host defense mechanisms. Clinical differentiation of the site of UTI is important. Pyelonephritis, or upper UTI, refers to infection of the renal parenchyma, which manifests as flank pain, fever, and systemic manifestations such as nausea, vomiting, or diarrhea. These patients are at risk of renal scarring. Cystitis, or lower UTI, is infection of the urinary bladder, which usually presents with symptoms of bladder irritation, dysuria, urinary frequency or hesitancy, and low-grade abdominal pain in the absence of systemic manifestations such as fever. Clinical manifestations of UTI are also age dependent. Apart from fever, older children can express and localize flank pain associated with pyelonephritis compared with infants with pyelonephritis, who may present with a combination of symptoms that include fever, irritability, excessive crying, diarrhea, and poor feeding. In young infants 
and children, fever is of special importance as a clinical marker of renal parenchymal involvement (pyelonephritis). As acknowledged by the American Academy of Pediatrics (AAP) in its practice parameters, the presence of high fever $\left(\geq 39^{\circ} \mathrm{C}\right)$ with clinical diagnosis of UTI is an important indicator of pyelonephritis compared with no fever $\left(\leq 38^{\circ} \mathrm{C}\right)$ in those with cystitis $[12,13]$. Indirect tests of inflammation [elevated peripheral white blood cell (WBC) count, elevated C-reactive protein (CRP)] can provide helpful guidance. The use of dimercaptosuccinate (DMSA) scan to differentiate the site of infection is discussed separately.

Diagnosing UTI requires appropriate collection of uncontaminated urine sample for analysis and culture. The technique of obtaining the urine can affect sample quality. It is recommended to collect urine by clean catch in children who are toilet trained. In infants and younger children, urine should be obtained by urinary catheterization or suprapubic aspiration. Collection of urine with adhesive bags to the perineal area has no role in diagnosing UTI due to the high risk of contamination. For a prompt diagnosis, urine is examined by dipstick and microscopy. Urine dipstick is an inexpensive and a readily available technique. The presence of either leukocyte esterase (LE) and/or nitrite is interpreted as a positive dipstick test [14], whereas blood and protein are poor indicators of UTI. Urine microscopy is performed to look for the presence of WBC or bacteria, and its sensitivity and specificity are better with uncentrifuged urine and Gram staining of the sample. Urine Gram stain for bacteria has a better sensitivity (91\%) and specificity (96\%) than all other rapid tests used alone or in combination [14] and when positive can guide therapy in children suspected of having UTI. When uncentrifuged urine is examined microscopically, pyuria is defined by $\geq 10$ $\mathrm{WBC} / \mathrm{mm}^{3}$ and bacteriuria by the presence of any bacteria per 10 oil immersion field of Gram-stained smear. Table 1 summarizes data from a recent meta-analysis by Williams et al. [14] evaluating rapid urine tests and comparing the accuracy of dipstick with microscopy. They concluded that Gram stain is the single best rapid test but still cannot replace urine culture. The study also concluded that either LE or nitrite positivity can be interpreted as positive dipstick testing.

Urine culture remains the reference standard for diagnosing UTI. However, because it requires a minimum of 18 hours before a result is known, the rapid tests are often used to guide the initial management. Accepted colony count criteria for a probable UTI diagnosis are summarized in Table $2[15,16]$. Increasing the acceptable colony count for UTI diagnosis has been suggested to decrease the false positive rate [17].

\section{Asymptomatic bacteriuria}

Asymptomatic bacteriuria (ABU) is defined as the growth of a significant number of a single organism [often> 100,000 colony-forming units $(\mathrm{CFU}) / \mathrm{ml}$ ] from a urine sample of an asymptomatic child with no pyuria. It is often an incidental finding and can be demonstrated on repeat urine cultures. The bacterium isolated is most often an $E$. coli strain of low virulence that colonizes the urinary tract and does not have significant ability to damage the kidneys [18]. Antibiotics should not be given to eradicate ABU [19-22]. ABU is also observed in children with neurogenic bladder, particularly if the patient is on clean intermittent catheterization, but studies have not shown increased risk of renal scarring or the need for prophylactic antibiotics in this group [19]. Patients with neurogenic bladder very often also have increased number of WBC in their urine, which makes UTI diagnosis difficult.

\section{Renal imaging in UTI}

The rationale for renal imaging is to identify risk factors and abnormalities of the genitourinary tract that can be modified to decrease the likelihood of recurrent UTI and renal scarring.

\section{Renal ultrasound}

Renal ultrasound is useful for detecting renal abscess, hydronephrosis, congenital abnormalities, and sometimes stones. It has a lower sensitivity for diagnosing pyelonephritis than DMSA; abnormalities compatible with pyelonephritis were reported in $20-69 \%$ of patients by ultrasound compared with $40-92 \%$ by DMSA [23]. Ultrasound has limited usefulness for assessing the presence of renal scarring; a study by Ahmed et al. [24] showed that renal

Table 1 Sensitivity and specificity of rapid urine tests. Adapted with modification from [14], with permission

\begin{tabular}{|c|c|c|c|c|c|c|}
\hline & WBC & Gram stain & LE & Nitrite & Either LE or nitrite & Both LE and nitrite \\
\hline Sensitivity & $74 \%$ & $91 \%$ & $79 \%$ & $49 \%$ & $88 \%$ & $45 \%$ \\
\hline Specificity & $86 \%$ & $96 \%$ & $87 \%$ & $98 \%$ & $79 \%$ & $98 \%$ \\
\hline
\end{tabular}

$W B C$ white blood cells, $L E$ leukocyte esterase 
Table 2 Diagnosing urinary tract infection (UTI) by urine culture

\begin{tabular}{lll}
\hline Collection method & Colony count (CFU/ml) & Probability of infection (\%) \\
\hline Suprapubic aspiration & Any growth & $>99 \%$ \\
Catheterization & $>10^{5}$ & $95 \%$ \\
& $10^{4}-10^{5}$ & Infection likely \\
Clean-catch, midstream urine & $>10^{4}$ (boy) & Infection likely \\
& $\geq 10^{5}$ (girl) (3 specimens) & $95 \%$ \\
& $\geq 10^{5}$ (girl) (2 specimens) & $90 \%$ \\
& $\geq 10^{5}$ (girl) (1 specimen) & $80 \%$ \\
\hline
\end{tabular}

CFU colony-forming units

Adapted with modification from [16], with permission over the actual value of these studies in altering the management and final outcome. The AAP, in its practice parameters published in 1999, recommends renal ultrasound and VCUG or RNC be performed in any infant or child ( 2 months to 2 years of age) after a first UTI [12]. In 2007 , in an effort to reduce the imaging burden of UTI work-up, the National Institute for Health and Clinical Excellence (NICE) of Great Britain published its recommendations on a more selective approach for renal imaging after UTI [27]. These recommendations are primarily based on patient age, response to antibacterial treatment, and typical versus atypical UTI. Further details on the guidelines are shown in Table 3. However, an argument has been made that this very selective approach can lead to delayed diagnosis of VUR and congenital abnormalities in these children [28, 29]. A retrospective analysis by Tse et al. revealed that selective imaging by NICE guidelines would have left a significant number of undiagnosed VUR and renal scars in infants $<6$ months of age [30]. More studies are needed to validate the NICE guidelines.

Another suggested approach to imaging in VUR is to replace the VCUG with a DMSA scan from the top-down approach; VCUG can then be performed if ultrasound and DMSA are abnormal [31, 32]. However, it has been shown recently that DMSA scan has limited ability in diagnosing VUR and replacing VCUG for evaluating children with their first UTI. Furthermore, the issue of differences in methodology used by different medical centers and the interobserver variability in scan interpretation need to be kept in mind [33]. A more definitive answer to the question of imaging is still lacking, and more evidence is needed to validate any of the current suggested approaches. The treating clinician should be aware of the available renal imaging options and their appropriate use in a particular child, which depends on patient age, VUR severity, presence or absence of renal scarring, and UTI frequency.

\section{UTI treatment}

UTI treatment depends on infection location (cystitis vs. pyelonephritis), patient's age, severity of presentation, and

is debatable because of the doubtful evidence and concerns 
Table 3 National Institute for Health and Clinical Excellence (NICE) imaging guidelines

\begin{tabular}{llll}
\hline & Responds well to treatment within $48 \mathrm{~h}$ & Atypical UTI $^{\mathrm{a}}$ & Recurrent UTI $^{\mathrm{b}}$ \\
\hline Age $<6$ months & Ultrasound $^{\mathrm{c}}$ & Ultrasound, DMSA and VCUG $^{\text {Ultrasound, DMSA and VCUG }}$ \\
Age 6 months-3 years & None & Ultrasound and DMSA $^{\mathrm{d}}$ & Ultrasound and DMSA $^{\mathrm{d}}$ \\
Age $>3$ years & None & Ultrasound $^{\text {Ultrasound and DMSA }}$ \\
\hline
\end{tabular}

UTI urinary tract infection, DMSA dimercaptosuccinate, $V C U G$ voiding cystourethrogram

${ }^{a}$ Non-Escherechia coli UTI: seriously ill, poor urine flow, abdominal or bladder mass, raised creatinine, septicemia, failure to respond to treatment with suitable antibiotics within $48 \mathrm{~h}$

${ }^{\mathrm{b}}$ Two or more episodes of UTI with acute pyelonephritis/upper urinary tract infection, or

one episode of UTI with acute pyelonephritis/upper urinary tract infection plus one or more episode of UTI with cystitis/lower urinary tract infection, or

three or more episodes of UTI with cystitis/lower urinary tract infection

${ }^{\mathrm{c}}$ If ultrasound is abnormal, consider a VCUG

${ }^{\mathrm{d}}$ Consider VCUG if dilatation on ultrasound, poor urine flow, non- $E$. coli infection, family history of VUR

the antimicrobial resistance pattern in the community. Empiric therapy for UTI should be initiated after appropriate urine specimen for culture has been obtained. Children $<24$ months of age suspected to have UTI should be treated as having pyelonephritis, whereas a more symptombased approach can be followed in older children.

\section{Treatment promptness}

It is believed that prompt antibiotic treatment of UTI diminishes the risk of renal scarring [12, 34]. However, two recent studies, by Hewitt et al. [35] and Doganis et al. [36], demonstrated that early treatment $(<1$ day of fever) of acute pyelonephritis in infants and young children had no significant effect on the incidence of subsequent renal scarring when compared with children treated after $24 \mathrm{~h}$. However, Doganis et al. showed that early and appropriate treatment, especially during the first $24 \mathrm{~h}$ after symptom onset, may diminish the likelihood of renal involvement during the acute phase of the infection [36]. The study included a smaller number of patients treated after 4 days compared with patients treated in $<1$ day. Also, it should still be kept in mind that even though these studies showed no evidence of renal damage following delayed treatment, it is not advisable to delay treatment of a sick patient when UTI is diagnosed. Patients with pyelonephritis can have complications other than scarring when treatment is delayed, such as sepsis and abscess formation.

Oral versus parenteral therapy

The AAP practice parameter guidelines published in 1999 recommend that well-appearing children between 2 months and 2 years of age with UTI can be treated with orally or parenterally administered antibiotics [12]. A 2007 Cochrane Review of 23 randomized and quasirandomized controlled studies showed no significant difference in persistent kidney damage at 6-12 months or in fever duration between orally administered antibiotic therapy for 1014 days and intravenously administered (IV) antibiotic therapy for 3 days followed by oral therapy for 10 days. Also, no significant difference in persistent kidney damage was found between initial IV therapy (3-4 days) followed by oral therapy and IV therapy for the entire treatment duration (7-14 days) [37]. Few other studies had similar conclusions when oral antibiotics were compared with parenteral therapy. A multicenter randomized controlled trial by Montini et al. showed that oral therapy was as effective as IV therapy followed by oral therapy for managing the first UTI episode [38]. However, most of these studies excluded high-risk children, such as those with significant renal scarring or genitourinary abnormali-
Table 4 Oral antibiotics for treating cystitis

\begin{tabular}{ll}
\hline Antibiotic & Dose \\
\hline Trimethoprim (TMP)-sulfamethoxazole & $8 \mathrm{mg}(\mathrm{TMP}) / \mathrm{kg} /$ day divided every $12 \mathrm{~h}$ \\
Nitrofurantoin & $5-7 \mathrm{mg} / \mathrm{kg} /$ day divided every $6 \mathrm{~h}$ \\
Amoxicillin & $25-45 \mathrm{mg} / \mathrm{kg} /$ day divided every $12 \mathrm{~h}$ \\
Amoxicillin-clavulanate & $25-45 \mathrm{mg}($ amoxicillin $) / \mathrm{kg} /$ day divided every $8-12 \mathrm{~h}$ \\
Cephalexin & $25-50 \mathrm{mg} / \mathrm{kg} /$ day divided every $6 \mathrm{~h}$ \\
Cefixime & $8 \mathrm{mg} / \mathrm{kg} /$ day divided every $12 \mathrm{~h}$ \\
\hline
\end{tabular}


ties. These high-risk children need to be identified and might benefit from initial parenteral therapy. In general, orally administered antibiotics can be used effectively on an outpatient basis to treat acute pyelonephritis in children $>2-3$ months who are clinically stable $[37,39]$. Suitable antibiotic choices are listed in Table 5. For lower UTI (cystitis), orally administered antibiotics for a short period (2-4 days) are generally effective.

Indications for hospitalization of any child with UTI include clinical urosepsis, laboratory evidence of bacteremia, immunocompromised patient, intolerance to oral intake, lack of adequate outpatient follow-up, or failure to respond to outpatient therapy. Managing febrile infants $<2-3$ month has not been well studied because these patients are often excluded from randomized controlled trials. They have a $10 \%$ concomitant risk of bacteremia [36], which prompts hospitalization and IV treatment with antibiotics until the systemic signs have resolved [3, 40, 41]. Complete septic work-up should be done in patients $<1$ month because UTI is most often secondary to hematogenous seeding rather than ascending infection.

\section{Antibiotic selection}

The choice of empirical antibiotics is guided by local resistance patterns, but coverage for $E$. coli as the most common infective organism should be considered. The North American Urinary Tract Infection Collaborative Trial report published in 2006 showed considerable E. coli resistance to $\beta$-lactam antibiotics $(37.7 \%)$ and trimethoprim-sulfamethoxazole (21.3\%) [42], which makes these agents inadequate first-line choices for treating serious UTI $[43,44]$. Prelog et al., in a retrospective study of children with febrile UTI, showed that $\beta$-lactam antibiotics and trimethoprim-resistant $E$. coli were more commonly seen in children with (35.8\%) than in those without (25.8\%) VUR [44]. However, E. coli remains largely sensitive to thirdgeneration cephalosporins (ceftriaxone, cefixime), aminoglycosides, and nitrofurantoin [43, 45]. Final antibiotic choice should be based on pathogen identification and sensitivity from urine culture. In infants $<1$ month, the most likely pathogens are E. coli and E. faecalis, which require empiric therapy with a $\beta$-lactam antibiotic and an aminoglycoside.
Orally administered antibiotics Second- and thirdgeneration cephalosporins are appropriate first-line treatment options for pyelonephritis. Alternatively, amoxicillinclavulanate, trimethoprim-sulfamethoxazole (TMP-SMX), and first-generation cephalosporins can be used with caution due to increasing resistance of $E$. coli. Fluoroquinolones (ciprofloxacin) are effective for $E$. coli but should not be used as first-line agents due to their questionable safety in children. Ciprofloxacin should be reserved for UTI caused by $P$. aeruginosa or other multi-drug-resistant organisms.

Parenteral therapy Third- or fourth-generation cephalosporins and aminoglycosides are appropriate for empiric treatment. When enterococcal UTI is suspected (urinary catheter, instrumentation of the urinary bladder, or genitourinary abnormalities), ampicillin should be included in treatment options. Gentamicin can be used parenterally as an adjunctive treatment in resistant organisms. However, its nephrotoxic properties limit its use. When gentamicin used, therapeutic levels and kidney function should be monitored (Table 6). After urine culture results are available, antibiotic treatment could be adjusted according to the sensitivity of the identified pathogen.

\section{Treatment duration and response}

The optimal treatment duration for pyelonephritis is 7-14 days, depending on administration route. In cases of severe pyelonephritis (acute lobar nephronia), prolonged parenteral therapy may help prevent progression to abscess [1]. For treating acute bacterial cystitis, several studies have shown that short treatment courses of 2-4 days are as effective as 7-14 days in eradicating lower UTI in children [46]. Treatment response in most patients is often noted within $24-48 \mathrm{~h}$ of antibiotic initiation. Children with worsening clinical condition (other than fever) might need imaging to rule out abscess formation, urinary stones, or obstruction. Revising the antibiotic selection might be needed. Repeat urine cultures after treatment are not needed in children who show clinical response to treatment [47, 48]. Children on prophylactic antibiotics for VUR might present a challenge to treatment as they are more likely to
Table 5 Orally administered antibiotics for treating pyelonephritis

\begin{tabular}{ll}
\hline Antibiotic & Dose \\
\hline Cefixime & $8 \mathrm{mg} / \mathrm{kg} /$ day divided every $12 \mathrm{~h}$ \\
Cefdinir & $14 \mathrm{mg} / \mathrm{kg} /$ day divided every $12 \mathrm{~h}$ \\
Amoxicillin-clavulanate & $25-45 \mathrm{mg}$ (amoxicillin)/kg/day divided every $8-12 \mathrm{~h}$ \\
Ciprofloxacin & $20-30 \mathrm{mg} / \mathrm{kg} /$ day divided every $12 \mathrm{~h}$ \\
\hline
\end{tabular}


Table 6 Parenteral antibiotics for treating pyelonephritis

\begin{tabular}{ll}
\hline Antibiotic & Dose \\
\hline Ampicillin & $100 \mathrm{mg} / \mathrm{kg} /$ day divided every $6 \mathrm{~h}$ \\
Cefotaxime & $100-200 \mathrm{mg} / \mathrm{kg} /$ day divided every $8 \mathrm{~h}$ \\
Ceftriaxone & $50-100 \mathrm{mg} / \mathrm{kg} /$ day divided every $12 \mathrm{~h}$ \\
Cefepime & $100 \mathrm{mg} / \mathrm{kg} /$ day divided every $12 \mathrm{~h}$ \\
Gentamicin & $7.5 \mathrm{mg} / \mathrm{kg} /$ day divided every $8 \mathrm{~h}$ \\
\hline
\end{tabular}

have UTI with a resistant organism [11, 49]. This is especially the case when prophylactic cephalosporins are used. Resistance has also been found to third-generation antibiotics in these children, but sensitivity to gentamicin remained high. This should be considered when choosing an antibiotic for these children, especially those who are acutely ill or not responding to initial empiric therapy. Children with anatomical defects, following genitourinary surgery, or repeated UTI and antibiotic courses, are more likely to have other causative organisms, such as Pseudomonas, Group B Streptococcus, S. aureus, or S. epidermidis, which should also be taken into consideration when these patients do not respond adequately to initial empiric therapy.

\section{Antimicrobial prophylaxis}

The role of VUR in causing UTI and the use of antimicrobial prophylaxis to prevent UTI with and without VUR is controversial. Regardless, the use of antimicrobial prophylaxis has been a standard practice for many decades. In 2006, a Cochrane Review by Williams et al. [50] identified eight randomized studies (618 children) that compared antibiotics with placebo or no treatment to prevent recurrent UTI. This analysis showed that antibiotics decreased the risk of positive urine culture compared with placebo. However, the authors concluded that more evidence in the form of properly randomized double-blinded trials is needed to support the routine use of antibiotic prophylaxis in preventing recurrent
UTI. Recently, there have been six randomized trials on antimicrobial prophylaxis for UTI [51-56], Table 7. Three of those included children with and without VUR [51, 54, 55]. Overall, these studies included patients from 0 to 18 years of age, with grades I-V VUR, if present. Garin et al.[51] and Montini et al.[54] reported no benefit with prophylaxis in children with and without VUR (grades I-III). The third study, by Craig et al. [55], which was placebo-controlled, showed a reduction in the absolute risk of UTI ( 6 percentage points) that did not vary with any stratifying variable (age, sex, reflux status, history of more than one UTI, or susceptibility of the causative organism for TMP-SMX). The other three randomized trials of antimicrobial prophylaxis for UTI included only patients with VUR grades I-IV, and patients' ages ranged from 0 to 3 years $[52,53,56]$. Roussey et al.[52] found no benefit to antibiotic prophylaxis in low-grade VUR except in boys with grade III reflux. Pennesi et al. [53] found no difference in UTI recurrence between prophylaxis and no prophylaxis in all patients $<30$ months. The Swedish Reflux Trial [56] studied 203 children (1-2 years of age) with grades III-IV reflux openly randomized into three groups: low-dose antibiotic prophylaxis, endoscopic therapy, and surveillance. The study demonstrated that UTI recurrence rate in girls $>1$ year with dilating VUR was higher than in boys and that this rate can be decreased with antibiotic prophylaxis and endoscopic treatment. There was no difference between the prophylaxis and endoscopic treatment groups. Fifty-seven percent of patients in the surveillance group suffered a UTI recurrence during follow-up. The study also showed that girls had a significantly higher rate of new renal damage on DMSA than boys at 2 years. Renal damage was most common in the surveillance group and showed a strong association with recurrent febrile UTI [57]. The results of these studies should be interpreted with caution because of some design-related limitations.

In 2007, NICE published its recommendations that healthcare professionals in the United Kingdom do not use antibiotic prophylaxis routinely in infants and children following firsttime UTI, and only selectively in recurrent UTI [27]. The

Table 7 Randomized trials on antimicrobial prophylaxis for urinary tract infections (UTI)

\begin{tabular}{|c|c|c|c|c|c|c|}
\hline Author and year & Patient age & $\begin{array}{l}\text { Total number of } \\
\text { patients in study }\end{array}$ & VUR status & $\begin{array}{l}\text { Number of patients } \\
\text { with VUR }\end{array}$ & VUR grade & Follow-up (months) \\
\hline Garin et al. [51] & 1 month-18 years & 218 & \pm VUR & 113 & I-III & 12 \\
\hline Roussey-Kesler et al. [52] & 1 month-3 years & 225 & + VUR & 225 & I-III & 18 \\
\hline Pennesi et al. [53] & 0-30 months & 100 & + VUR & 100 & II_IV & 24- 48 \\
\hline Montini et al. [54] & 2 months- 7 years & 338 & $\pm \mathrm{VUR}$ & 128 & I-III & 12 \\
\hline Craig et al. [55] & $0-18$ years & 576 & $\pm \mathrm{VUR}$ & 243 & $\mathrm{I}-\mathrm{V}$ & 12 \\
\hline Swedish Reflux Trial [56] & $1-2$ years & 203 & + VUR & 203 & III-IV & 24 \\
\hline
\end{tabular}

VUR vesicoureteral reflux 
Table 8 Initial management of a child $<1$ year old with vesicoureteral reflux (VUR) according to American Urological Association (AUA) guidelines
Continuous antibiotic prophylaxis

\begin{tabular}{lllll}
\hline & & Standard & Recommended & Option \\
VUR diagnosed after febrile UTI & All grades & - & $\checkmark$ & - \\
VUR diagnosed through screening & Grades I \& II & - & - & $\checkmark$ \\
& Grades III- V & - & $\checkmark$ & - \\
\hline
\end{tabular}

American Urological Association (AUA) published its guidelines on primary VUR management in September of 2010 based on the current evidence related to VUR management in children [6]. These guidelines are summarized in Tables 8, 9, and 10. The initial management of a child with VUR (Tables 8 and 9) is stratified by age, with a more conservative approach in children $<1$ year because of their increased morbidity with pyelonephritis and higher incidence of renal scarring. The statements made by AUA are graded with respect to the degree of flexibility in application. Standard is the most rigid statement policy; Recommendation has significantly less rigidity, being a statement with sufficient evidence to advocate for a particular clinical approach; Option offers the most flexibility when there is evidence of relatively equal strength to support more than one approach.

In view of all these studies and recommendations, VUR management is a subject of constant debate. The need for higher-quality evidence to guide management is increasing. The Randomized Intervention for Children with Vesicoureteral Reflux (RIVUR) funded by the US National Institutes of Health (NIH) is underway. It is a double-blind, randomized, placebo-controlled trial that started enrolling in 2007, which will evaluate the role of antimicrobial prophylaxis in children with grades I-IV VUR diagnosed after febrile UTI. Until more evidencebased practices evolve, the treating physician should be cautious when treating children with risk factors for recurrent UTI, including VUR. The clinician must decide whether the benefit of antibiotic use outweighs the risk and when surgical intervention might be a preferred option.

Table 9 Initial management of a child $>1$ year old with vesicoureteral reflux (VUR) according to American Urological Association (AUA) guidelines

\begin{tabular}{llll}
\hline & \multicolumn{2}{c}{ Continuous antibiotic prophylaxis } \\
\cline { 2 - 4 } & Standard & Recommended & Option \\
\hline $\begin{array}{l}\text { No recurrent febrile UTI, } \\
\text { BBD or renal cortical } \\
\text { anomalies }\end{array}$ & - & - & $\checkmark$ \\
$\begin{array}{l}\text { Recurrent febrile UTI, BBD, } \\
\text { or renal cortical anomalies }\end{array}$ & - & $\checkmark$ & \\
\hline
\end{tabular}

$B B D$ bladder and bowel dysfunction
Prophylactic antimicrobial choice

Antibiotics commonly used include TMP-SMX, trimethoprim, nitrofurantoin, and first-generation cephalosporins. Amoxicillin can be used in children $<2$ months, because TMP-SMX is contraindicated in this age group (Table 11).

Prophylaxis limitations

Antimicrobial resistance is a major concern with antibiotic prophylaxis. Cheng et al. [49], in a retrospective analysis, found that infection was less common in children on antibiotic prophylaxis compared with their initial episodes of UTI. Cephalosporins as prophylactic antibiotics compared with TMP-SMX are more likely to be associated with breakthrough UTI caused by extendedspectrum $\beta$-lactamase-producing organisms [49]. This could present as a problem of increasing difficulty of prescribing appropriate antibiotics when children present with recurrent UTI. Other problems with prophylaxis include compliance and parental concern over long-term antibiotic administration.

\section{Surgical treatment of VUR}

Surgical treatment is usually reserved for patients with high-grade VUR, recurrent UTI despite antibiotic prophylaxis, and noncompliance with prophylactic antibiotics. Open surgery has largely been replaced by endoscopic and laparoscopic techniques. Endoscopic treatment involving subureteral or intraureteral injection of a bulking agent with dextranomer/ hyaluronic acide (Deflux ${ }^{\circledR}$ ) is suggested as first-line treatment. Success rates are $98.1 \%$ for open and $83 \%$ for endoscopic surgery after injection [6]. The most recent AUA guidelines gave the option of surgical intervention, including open and endoscopic surgery, at the time of the initial diagnosis. The decision is affected by the patient's age, kidney status, reflux grade, and parental wishes [6]. The Swedish Reflux Trial report on VUR outcome demonstrated that endoscopic treatment resulted in a significantly higher resolution or downgrading of dilating VUR compared with prophylaxis and surveillance [58]. It also raised concern over the common reappearance of dilating VUR after 2 years from endoscopic treatment. 
Table 10 Breakthrough urinary tract infection (BT-UTI) management according to American Urological Association (AUA) guidelines

\begin{tabular}{|c|c|}
\hline Clinical scenario & Recommendation $(\mathrm{R}) /$ Option $(\mathrm{O})$ \\
\hline Symptomatic BT-UTI & $\mathrm{R}$ : Change of therapy guided by scenario \\
\hline Patient on CAP with febrile BT-UTI & R: Consider open or endoscopic surgical intervention \\
\hline $\begin{array}{l}\text { Patient on CAP with single febrile BT-UTI without evidence of existing or new } \\
\text { renal cortical abnormalities }\end{array}$ & $\begin{array}{l}\text { O: change to alternative antibiotics is an option before } \\
\text { surgical intervention }\end{array}$ \\
\hline Patient not on CAP with febrile BT-UTI & R: Initiation of CAP \\
\hline Patient not on CAP with nonfebrile UTI & O: Initiation of CAP \\
\hline All patients with BT-UTI & O: Surgical intervention \\
\hline
\end{tabular}

CAP continuous antibiotic prophylaxis

\section{Conclusion}

UTI is a common infection in children, with a potential risk for complications such as renal scarring. Appropriate UTI diagnosis and management is important. Management is aimed at treating the acute episode as well as preventing recurrences. Renal ultrasound after a first UTI is helpful in diagnosing some underlying congenital abnormalities that increase recurrence risk and that may need surgical intervention. VCUG and the DMSA renal scan remain the gold standards for diagnosing VUR and renal scarring, respectively. Decisions regarding antimicrobial prophylaxis or surgical intervention in children with VUR are primarily based on patient age, VUR severity, presence of renal scarring, UTI frequency, and voiding dysfunction.

\section{Multiple-choice questions}

(Answers appear following the reference list)

1. Which one of the following statements regarding UTI diagnosis is true?

a. Clean-catch urine sample can be used in all children

b. Uretheral catheterization or suprapubic aspiration should be performed in infants and newborn

Table 11 Prophylactic antimicrobial agents

\begin{tabular}{ll}
\hline Antibiotic & Dose \\
\hline Trimethoprim (TMP)-sulfamethoxazole & $2 \mathrm{mg} \mathrm{TMP} / \mathrm{kg} /$ day daily \\
Nitrofurantoin & $1-2 \mathrm{mg} / \mathrm{kg} / \mathrm{dose}$ daily \\
Cephalexin & $10 \mathrm{mg} / \mathrm{kg} / \mathrm{dose}$ daily \\
Amoxicillin & $10 \mathrm{mg} / \mathrm{kg} /$ dose daily \\
\hline
\end{tabular}

c. Uretheral catheterization has a lower likelihood of contamination compared with suprapubic aspiration

d. Periuretheral adhesive bag can be used in boys but not girls because of contamination risk

e. Any bacterial growth from a catheterized urine sample is considered significant

2. Of the following, which one is the most specific test for UTI by dipstick?
a. LE alone
b. Nitrite alone
c. Protein and blood
d. LE and nitrite
e. Protein and LE

3. Which one of the following characterizes asymptomatic bacteriuria?

a. Pyuria is present

b. Most commonly caused by Pseudomonas Aeruginosa

c. Antibiotic treatment is indicated

d. Can be a normal finding in children with neurogenic bladder

e. Increased risk of scarring if antibiotic prophylaxis is not used

4. Which of the following tests is the current gold standard for diagnosing renal scarring?
a. Ultrasound examination
b. Intravenous pyelography
c. DMSA renal scan
d. CT scan
e. Radionuclear cystography (RNC) 


\section{References}

1. Uhari M, Nuutinen M (1988) Epidemiology of symptomatic infections of the urinary tract in children. BMJ 297:450-452

2. Dunand BA (2009) Urinary Tract Infections. In: Avner ED HW, Niaudet P, Yoshikawa N. (ed) Pediatric Nephrology. Springer

3. Bell LE, Mattoo TK (2009) Update on childhood urinary tract infection and vesicoureteral reflux. Semin Nephrol 29:349-359

4. Conway PH, Cnaan A, Zaoutis T, Henry BV, Grundmeier RW, Keren R (2007) Recurrent urinary tract infections in children: risk factors and association with prophylactic antimicrobials. JAMA 298:179-186

5. Dai B, Liu Y, Jia J, Mei C (2010) Long-term antibiotics for the prevention of recurrent urinary tract infection in children: a systematic review and meta-analysis. Arch Dis Child 95:499-508

6. Peters CA, Skoog SJ, Arant BS Jr, Copp HL, Elder JS, Hudson RG, Khoury AE, Lorenzo AJ, Pohl HG, Shapiro E, Snodgrass WT, Diaz M (2010) Summary of the AUA guideline on management of primary vesicoureteral reflux in children. J Urol 184:1134-1144

7. Shaikh N, Ewing AL, Bhatnagar S, Hoberman A (2010) Risk of renal scarring in children with a first urinary tract infection: a systematic review. Pediatrics 126:1084-1091

8. Bensman A, Dunand O, UlinskiT (2009) Urinary Tract Infections. In: Avner ED, Harmon WE, Niaudet P, Yoshikawa N (Eds) Pediatric Nephrology. Springer, Berlin, pp 1299-1309

9. Akram M, Shahid M, Khan AU (2007) Etiology and antibiotic resistance patterns of community-acquired urinary tract infections in J N M C Hospital Aligarh, India. Ann Clin Microbiol Antimicrob 6:4

10. Chakupurakal R, Ahmed M, Sobithadevi DN, Chinnappan S, Reynolds T (2010) Urinary tract pathogens and resistance pattern. J Clin Pathol 63:652-654

11. Lutter SA, Currie ML, Mitz LB, Greenbaum LA (2005) Antibiotic resistance patterns in children hospitalized for urinary tract infections. Arch Pediatr Adolesc Med 159:924-928

12. American Academy of Pediatrics (1999) Practice parameter: the diagnosis, treatment, and evaluation of the initial urinary tract infection in febrile infants and young children. American Academy of Pediatrics. Committee on quality improvement. Subcommittee on urinary tract infection. Pediatrics 103:843-852

13. Winberg J, Andersen HJ, Bergstrom T, Jacobsson B, Larson H, Lincoln K (1974) Epidemiology of symptomatic urinary tract infection in childhood. Acta Paediatr Scand Suppl:1-20

14. Williams GJ, Macaskill P, Chan SF, Turner RM, Hodson E, Craig JC (2010) Absolute and relative accuracy of rapid urine tests for urinary tract infection in children: a meta-analysis. Lancet Infect Dis 10:240-250

15. Keren R, Carpenter MA, Hoberman A, Shaikh N, Matoo TK, Chesney RW, Matthews R, Gerson AC, Greenfield SP, Fivush B, McLurie GA, Rushton HG, Canning D, Nelson CP, Greenbaum L, Bukowski T, Primack W, Sutherland R, Hosking J, Stewart D, Elder J, Moxey-Mims M, Nyberg L (2008) Rationale and design issues of the Randomized Intervention for Children With Vesicoureteral Reflux (RIVUR) study. Pediatrics 122(Suppl 5):S240-S250

16. Hellerstein $S$ (1982) Recurrent urinary tract infections in children. Pediatr Infect Dis 1:271-281

17. Coulthard MG, Kalra M, Lambert HJ, Nelson A, Smith T, Perry JD (2010) Redefining urinary tract infections by bacterial colony counts. Pediatrics 125:335-341

18. Linshaw M (1996) Asymptomatic bacteriuria and vesicoureteral reflux in children. Kidney Int 50:312-329

19. Ottolini MC, Shaer CM, Rushton HG, Majd M, Gonzales EC, Patel KM (1995) Relationship of asymptomatic bacteriuria and renal scarring in children with neuropathic bladders who are practicing clean intermittent catheterization. J Pediatr 127:368 372
20. Bensman A (2002) Should children with asymptomatic bacteriuria $(\mathrm{ABU})$ undergo imaging studies of the urinary tract? Pediatr Nephrol 17:76-77

21. Hansson S, Martinell J, Stokland E, Jodal U (1997) The natural history of bacteriuria in childhood. Infect Dis Clin North Am 11:499-512

22. Wettergren B, Hellstrom M, Stokland E, Jodal U (1990) Six year follow up of infants with bacteriuria on screening. BMJ 301:845-848

23. Lavocat MP, Granjon D, Allard D, Gay C, Freycon MT, Dubois F (1997) Imaging of pyelonephritis. Pediatr Radiol 27:159-165

24. Ahmed M, Eggleston D, Kapur G, Jain A, Valentini RP, Mattoo TK (2008) Dimercaptosuccinic acid (DMSA) renal scan in the evaluation of hypertension in children. Pediatr Nephrol 23:435-438

25. Lebowitz RL, Olbing H, Parkkulainen KV, Smellie JM, Tamminen-Mobius TE (1985) International system of radiographic grading of vesicoureteric reflux. International reflux study in children. Pediatr Radiol 15:105-109

26. Ditchfield MR, Summerville D, Grimwood K, Cook DJ, Powell HR, Sloane R, Nolan TM, de Campo JF (2002) Time course of transient cortical scintigraphic defects associated with acute pyelonephritis. Pediatr Radiol 32:849-852

27. Baumer JH, Jones RW (2007) Urinary tract infection in children, National Institute for Health and Clinical Excellence. Arch Dis Child Educ Pract Ed 92:189-192

28. Coulthard MG (2008) Is reflux nephropathy preventable, and will the NICE childhood UTI guidelines help? Arch Dis Child 93:196-199

29. Coulthard MG (2007) NICE on childhood UTI: Nasty processes produce nasty guidelines. BMJ 335:463; author reply 463-464

30. Tse NK, Yuen SL, Chiu MC, Lai WM, Tong PC (2009) Imaging studies for first urinary tract infection in infants less than 6 months old: can they be more selective? Pediatr Nephrol 24:1699-1703

31. Herz D, Merguerian P, McQuiston L, Danielson C, Gheen M, Brenfleck L (2010) 5-year prospective results of dimercapto-succinic acid imaging in children with febrile urinary tract infection: proof that the top-down approach works. J Urol 184:1703-1709

32. Lee MD, Lin CC, Huang FY, Tsai TC, Huang CT, Tsai JD (2009) Screening young children with a first febrile urinary tract infection for high-grade vesicoureteral reflux with renal ultrasound scanning and technetium-99 m-labeled dimercaptosuccinic acid scanning. J Pediatr 154:797-802

33. Ziessman HA, Majd M (2009) Importance of methodology on (99 m)technetium dimercapto-succinic acid scintigraphic image quality: imaging pilot study for RIVUR (Randomized Intervention for Children With Vesicoureteral Reflux) multicenter investigation. J Urol 182:272-279

34. Hiraoka M, Hashimoto G, Tsuchida S, Tsukahara H, Ohshima Y, Mayumi M (2003) Early treatment of urinary infection prevents renal damage on cortical scintigraphy. Pediatr Nephrol 18:115-118

35. Hewitt IK, Zucchetta P, Rigon L, Maschio F, Molinari PP, Tomasi L, Toffolo A, Pavanello L, Crivellaro C, Bellato S, Montini G (2008) Early treatment of acute pyelonephritis in children fails to reduce renal scarring: data from the Italian renal infection study trials. Pediatrics 122:486-490

36. Doganis D, Siafas K, Mavrikou M, Issaris G, Martirosova A, Perperidis G, Konstantopoulos A, Sinaniotis K (2007) Does early treatment of urinary tract infection prevent renal damage? Pediatrics 120:e922-e928

37. Hodson EM, Willis NS, Craig JC (2007) Antibiotics for acute pyelonephritis in children. Cochrane Database Syst Rev: CD003772

38. Montini G, Toffolo A, Zucchetta P, Dall'Amico R, Gobber D, Calderan A, Maschio F, Pavanello L, Molinari PP, Scorrano D, Zanchetta S, Cassar W, Brisotto P, Corsini A, Sartori S, Da Dalt L, Murer L, Zacchello G (2007) Antibiotic treatment for pyelonephritis in children: multicentre randomised controlled noninferiority trial. BMJ 335:386 
39. Hoberman A, Wald ER (1997) Urinary tract infections in young febrile children. Pediatr Infect Dis J 16:11-17

40. Pantell RH, Newman TB, Bernzweig J, Bergman DA, Takayama JI, Segal M, Finch SA, Wasserman RC (2004) Management and outcomes of care of fever in early infancy. JAMA 291:1203-1212

41. Williams G, Craig, C. (2008) Diagnosis and Management of Urinary Tract Infections. In: Geary D, Schaefer F (ed) Comprehensive Pediatric Nephrology. Mosby, pp 539-548

42. Zhanel GG, Hisanaga TL, Laing NM, DeCorby MR, Nichol KA, Weshnoweski B, Johnson J, Noreddin A, Low DE, Karlowsky JA, Hoban DJ (2006) Antibiotic resistance in Escherichia coli outpatient urinary isolates: final results from the North American Urinary Tract Infection Collaborative Alliance (NAUTICA). Int J Antimicrob Agents 27:468-475

43. Zhanel GG, Hisanaga TL, Laing NM, DeCorby MR, Nichol KA, Palatnik LP, Johnson J, Noreddin A, Harding GK, Nicolle LE, Hoban DJ (2005) Antibiotic resistance in outpatient urinary isolates: final results from the North American Urinary Tract Infection Collaborative Alliance (NAUTICA). Int J Antimicrob Agents 26:380-388

44. Prelog M, Schiefecker D, Fille M, Wurzner R, Brunner A, Zimmerhackl LB (2008) Febrile urinary tract infection in children: ampicillin and trimethoprim insufficient as empirical monotherapy. Pediatr Nephrol 23:597-602

45. Fabre R, Merens A, Lefebvre F, Epifanoff G, Cerutti F, Pupin H, Tardif D, Cavallo JD, Ternois I (2010) Susceptibility to antibiotics of Escherichia coli isolated from community-acquired urinary tract infections. Méd Mal Infect 40:555-559

46. Michael M, Hodson EM, Craig JC, Martin S, Moyer VA (2003) Short versus standard duration oral antibiotic therapy for acute urinary tract infection in children. Cochrane Database Syst Rev: CD003966

47. Oreskovic NM, Sembrano EU (2007) Repeat urine cultures in children who are admitted with urinary tract infections. Pediatrics 119:e325-e329

48. Currie ML, Mitz L, Raasch CS, Greenbaum LA (2003) Follow-up urine cultures and fever in children with urinary tract infection. Arch Pediatr Adolesc Med 157:1237-1240

49. Cheng CH, Tsai MH, Huang YC, Su LH, Tsau YK, Lin CJ, Chiu CH, Lin TY (2008) Antibiotic resistance patterns of communityacquired urinary tract infections in children with vesicoureteral reflux receiving prophylactic antibiotic therapy. Pediatrics 122:1212-1217

50. Williams GJ, Wei L, Lee A, Craig JC (2006) Long-term antibiotics for preventing recurrent urinary tract infection in children. Cochrane Database Syst Rev 3:CD001534

51. Garin EH, Olavarria F, Garcia Nieto V, Valenciano B, Campos A, Young L (2006) Clinical significance of primary vesicoureteral reflux and urinary antibiotic prophylaxis after acute pyelonephri- tis: a multicenter, randomized, controlled study. Pediatrics 117:626-632

52. Roussey-Kesler G, Gadjos V, Idres N, Horen B, Ichay L, Leclair MD, Raymond F, Grellier A, Hazart I, de Parscau L, Salomon R, Champion G, Leroy V, Guigonis V, Siret D, Palcoux JB, Taque S, Lemoigne A, Nguyen JM, Guyot C (2008) Antibiotic prophylaxis for the prevention of recurrent urinary tract infection in children with low grade vesicoureteral reflux: results from a prospective randomized study. J Urol 179:674-679, discussion 679

53. Pennesi M, Travan L, Peratoner L, Bordugo A, Cattaneo A, Ronfani L, Minisini S, Ventura A (2008) Is antibiotic prophylaxis in children with vesicoureteral reflux effective in preventing pyelonephritis and renal scars? A randomized, controlled trial. Pediatrics 121:e1489-e1494

54. Montini G, Rigon L, Zucchetta P, Fregonese F, Toffolo A, Gobber D, Cecchin D, Pavanello L, Molinari PP, Maschio F, Zanchetta S, Cassar W, Casadio L, Crivellaro C, Fortunati P, Corsini A, Calderan A, Comacchio S, Tommasi L, Hewitt IK, Da Dalt L, Zacchello G, Dall'Amico R (2008) Prophylaxis after first febrile urinary tract infection in children? A multicenter, randomized, controlled, noninferiority trial. Pediatrics 122:1064-1071

55. Craig JC, Simpson JM, Williams GJ, Lowe A, Reynolds GJ, McTaggart SJ, Hodson EM, Carapetis JR, Cranswick NE, Smith G, Irwig LM, Caldwell PH, Hamilton S, Roy LP (2009) Antibiotic prophylaxis and recurrent urinary tract infection in children. $\mathrm{N}$ Engl J Med 361:1748-1759

56. Brandstrom P, Esbjorner E, Herthelius M, Swerkersson S, Jodal U, Hansson S (2010) The Swedish reflux trial in children: III. Urinary tract infection pattern. J Urol 184:286-291

57. Brandstrom P, Neveus T, Sixt R, Stokland E, Jodal U, Hansson S (2010) The Swedish reflux trial in children: IV. Renal damage. J Urol 184:292-297

58. Holmdahl G, Brandstrom P, Lackgren G, Sillen U, Stokland E, Jodal U, Hansson S (2010) The Swedish reflux trial in children: II. Vesicoureteral reflux outcome. J Urol 184:280-285

Answers:

1. b. Uretheral catheterization or suprapubic aspiration should be performed in infants and newborn

2. d. LE and nitrite

3. d. Can be a normal finding in children with neurogenic bladder

4. c. DMSA renal scan 